\title{
Nolite te bastardes carborundorum: a narrativa testemunhal em o conto da aia, de Margaret Atwood
}

\author{
Nolite te bastardes carborundorum: the survival's \\ narrative in the handmaid's tale, by Margaret Atwood
}

\author{
Nolite te bastardes carborundorum: la narrativa \\ testimonial en the handmaid's tale, de Margaret Atwood
}

\author{
iD Adriana Souza Machado Santana \\ Universidade Federal de Goiás (UFG), Goiânia, Goiás, Brasil. Bolsista PIBIC/CNPq \\ (2019-2020). \\ E-mail: drica.chase7@gmail.com \\ iD Marcelo Ferraz de Paula \\ Universidade Federal de Goiás (UFG), Goiânia, Goiás, Brasil. Membro do quadro \\ permanente de docentes do PPGLL (UFG). Pesquisador do CNPQ (Bolsista PQ 2). \\ E-mail: marcelo2867@ufg.br.
}

\begin{abstract}
Resumo: $O$ artigo analisa a narrativa da personagem Offred, do romance $O$ Conto da Aia, concentrando-se no exame de suas configurações testemunhais. Em diálogo com estudos de Agamben (2008), Felman (2000), Seligmann-Silva $(2003,2005)$ e Gagnebin (2009) sobre o testemunho, buscamos evidenciar como a construção ficcional da obra tensiona o gênero romance, incorporando em sua tessitura formal impasses éticos e estéticos que são próprios da chamada "literatura de testemunho".
\end{abstract}

Palavras-chave: Testemunho; Memória; Margaret Atwood; Romance contemporâneo. 


\begin{abstract}
This paper analyses the narrative of Offred in the novel The Hadmaid's Tale, focusing on the exploration of its testimonial composition. In dialogue with the works of Agamben (2008), Felman (2000), SeligmannSilva (2002) and Gagnebin (2009) about testimony, we demonstrate how the fictional construction of the narrative incorporates, in its constitution, the formal imprints and the ethical and esthetical dilemmas that are quintessential of the testimony literature.
\end{abstract}

Keywords: Testimony; Memoir; Margaret Atwood; Contemporary novel.

Resumen: El artículo analiza la narración de la personaje Offred, en la novela The handmaid's tale (El cuento de la criada), centrándose en el examen de sus configuraciones testimoniales. En diálogo con los estudios de Agamben (2008), Felman (2000), Seligmann-Silva (2003, 2005) y Gagnebin (2009), buscamos mostrar cómo la construcción ficcional de la obra tensiona el género novelístico, incorporando en su tejido formal cuestiones éticas y estéticas propias de la llamada "literatura de testimonio".

Palabras clave: Testimonio; Memoria; Margarita Atwood; Novela contemporánea.

Esse entalhe, feito de um lápis cravado muitas vezes no verniz gasto da carteira, tem o páthos de todas as civilizações desaparecidas. É como a impressão de uma mão na pedra. Quem quer que tenha feito aquilo algum dia esteve vivo. Margaret Atwood. O Conto da Aia.

Submissão 05 maio de 2021.

Aceite 17 de outubro de 2021.

Publicado em 03 de fevereiro de 2022 
Nolite te bastardes carborundorum: a narrativa testemunhal em o conto da aia... Adriana Souza Machado Santana • Marcelo Ferraz de Paula

\section{Introdução}

A palavra testemunho desperta várias interpretações, pois se trata de um conceito abordado em diversas áreas do conhecimento. Numa perspectiva etimológica, existem, em latim, dois termos na origem de "testemunha": terstis e superstes, sendo definidos respectivamente como "aquele que se põe como terceiro em um processo ou em um litígio entre dois contendores" (AGAMBEN, 2008, p. 27) e "aquele que viveu algo, atravessou até o final um evento e pode, portanto, dar testemunho disso" (AGAMBEN, 2008, p. 27). Terstis ressalta o vínculo do testemunho com o sentido da visão e a possibilidade de se fornecer uma "verdade" atestável, inclusive numa dimensão jurídica, enquanto superstes liga-se à necessidade (e a dificuldade) de narrar sentida por aqueles que passaram por uma experiência dilaceradora. Em sua acepção moderna mais corrente, o dicionário define testemunha como "pessoa chamada a assistir certos atos autênticos ou solenes" (FERREIRA, 2008, p. 774) e "pessoa que viu ou ouviu algo, ou que é chamada a depor sobre o que viu ou ouviu" (FERREIRA, 2008, p. 774). Dessa manei$\mathrm{ra}$, podemos concluir que a testemunha é quem está presente em uma situação de importância e/ou singularidade, e que auxilia na formulação de uma versão fidedigna do que está ocorrendo ou ocorreu.

Como se sabe, o século XX foi amplamente marcado por guerras, genocídios e regimes totalitários, gerando uma vasta produção de narrativas testemunhais. Tais obras, escritas por sobreviventes das diversas catástrofes que abalaram o período, ganharam uma forte projeção cultural ao longo das últimas décadas, conforme as questões em torno da memória, dos direitos humanos, das identidades, bem como a ameaça constante de recaída na barbárie, se impuseram como temas de relevo no debate público.

O vínculo entre testemunho, literatura e a violência de estado racionalmente administrada consolidou-se como uma importante fonte de reflexão sobre o nosso tempo (MARCO, 2004). O testemu- 
Nolite te bastardes carborundorum: a narrativa testemunhal em o conto da aia... Adriana Souza Machado Santana • Marcelo Ferraz de Paula

nho abala categorias centrais da Teoria Literária, como a autonomia estética e o princípio de ficcionalização próprios da expressão literária moderna (SELIGMANN-SILVA, 2003a). O discurso híbrido do testemunho frequenta as fronteiras dos gêneros biográfico-memorialístico, romanesco, poético, jornalístico, jurídico e histórico - sem se esgotar em nenhum deles - e por isso tem levado a um reexame de noções basilares que a teoria forneceu para explicar a natureza do literário e seus vínculos com a realidade, o mundo e a vida. Portanto, mesmo quando incorporado em obras abertamente ficcionais, como o romance examinado neste artigo, as marcas testemunhais constituem amiúde um fator de desestabilização, seja dos gêneros literários tradicionais seja em relação aos processos de mediação entre o texto literário e os eventos históricos.

Em "Educação e crise, ou as vicissitudes do ensinar", Shoshana Felman (2000, p. 17) chama atenção para o modo como o testemunho se tornou "uma modalidade crucial de nossa relação com os acontecimentos de nosso tempo - com o trauma da história contemporânea". Citando o escritor Elie Wiesel, sobrevivente da Shoah, a autora compreende o testemunho como o "modo literário" típico de nosso tempo, aquele que captaria com a precisão possível as atrocidades de nossa era: "Se os gregos inventaram a tragédia, os romanos a epístola e a Renascença o soneto, nossa geração inventou uma nova literatura, aquela do testemunho" (WIESEL, 1977 apud FELMAN, 2000, p. 18).

O impacto do testemunho nas práticas literárias e discursivas está ligado à proliferação de textos memoriais escritos por sobreviventes das catástrofes, com destaque para a chamada "literatura do holocausto", que após o fim da Segunda Guerra Mundial passou a receber atenção acadêmica e editorial mais sistemática. Entretanto, sua relevância cultural está longe de se esgotar na produção memorialística das testemunhas primárias: a literatura como um todo sofre essa inflexão, de tal forma que mesmo obras escritas sem o compromisso testemunhal imediato e por artistas que não sofreram diretamente os horrores do século têm o seu estatuto atravessado pelo fenômeno e podem manifestar uma dimensão 
Nolite te bastardes carborundorum: a narrativa testemunhal em o conto da aia... Adriana Souza Machado Santana • Marcelo Ferraz de Paula

pós-traumática. O testemunho está, portanto, no centro de uma guinada subjetiva da literatura moderna e contemporânea, a qual, por uma série de fatores e com diversidade de formas, abalou a separação tradicional entre ficção, confissão e realidade, revisitou, com ceticismo, a autonomia da literatura e impulsionou diversos subgêneros nos quais a escrita de vida está presente, com inúmeros níveis de estetização, da autobiografia à autoficção.

Assim, conforme Márcio Seligmann-Silva (2005),

ao invés de se falar em "literatura de testemunho", que não é um gênero, percebemos agora uma face da literatura que vem à tona na nossa época de catástrofes e que faz com que toda a história da literatura - após duzentos anos de auto-referência - seja revista a partir do questionamento da sua relação e do seu compromisso com o "real". Nos estudos de testemunho deve-se buscar caracterizar o "teor testemunhal" que marca toda obra literária, mas que aprendemos a detectar a partir da concentração desse teor na literatura e escritura do século XX. Esse teor indica diversas modalidades de relação metonímica entre o "real" e a escritura. (SELIGMANN-SILVA, 2005, p. 85 , grifo do autor).

Em O Conto da Aia, romance da escritora canadense Margaret Atwood, publicado pela primeira vez em 1985, esse teor testemunhal é bastante evidente. O romance é narrado por Offred, uma mulher que desempenha o papel de aia no território de Gilead, uma sociedade teocrática distópica situada onde hoje ficam os Estados Unidos da América. A estrutura social de Gilead é altamente misógina e repressiva: as mulheres não podem ler, sair de casa desacompanhadas ou escolher com quem desejam se relacionar, estando presas a seus papéis domésticos, sempre com uma vigília implacável e sufocante de agentes de Estado infiltrados em todos os níveis da vida pública e privada. Nessa divisão repressora, as aias são propriedades do Estado e responsáveis por ter filhos dos Comandantes (alto escalão do governo) no lugar de suas mulheres 
Nolite te bastardes carborundorum: a narrativa testemunhal em o conto da aia... Adriana Souza Machado Santana • Marcelo Ferraz de Paula

inférteis. São tratadas como "úteros de duas pernas, apenas isso: receptáculos sagrados, cálices ambulantes" ${ }^{1}$ (ATWOOD, 2017a, p. 165). Offred então narra a sua vida cotidiana antes e durante o regime, expondo a repressão do Estado, seus desejos e temores em meio a constante luta pela sobrevivência.

A fortuna crítica em torno do romance é vasta e nela podemos mapear algumas linhas privilegiadas de leitura da obra: há destaque, obviamente, para os estudos de gênero, que abordam a crítica social feita no romance e as relações entre sexo, poder, patriarcado, política e religião. Os estudos também procuram com frequência compreender a apropriação que Atwood faz da ficção científica e das narrativas distópicas, salientando o diálogo tácito que mantém com obras clássicas como 1984, de Orwell, Admirável Mundo Novo, de Huxley, e Fahrenheit 451, de Ray Bradbury. Outro tipo fértil de abordagem volta-se para o intertexto com a Bíblia especialmente o Antigo Testamento, citado diversas vezes no romance, desde a epígrafe do livro. As referências bíblicas ora são literais ora deliberadamente adulteradas pelas lideranças políticas do regime, como justificativa e inspiração para a organização social opressiva de Gilead, cujo próprio nome remete ao texto bíblico, significando sugestivamente "monte do testemunho" (GÊNESIS, 31; 21).

Por outro lado, não encontramos em nosso levantamento bibliográfico pesquisas que enfatizem especificamente a construção testemunhal do romance e é essa lacuna que julgamos oportuno ajudar a sanar neste artigo. Segundo a autora, em seu painel na Bookcon de 2017, suas leituras sobre a "literatura de testemunho" foram fundamentais no processo de construção da obra, indício de que esse aspecto ainda merece maior atenção da crítica:

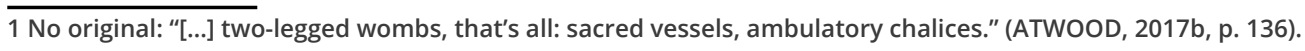


Nolite te bastardes carborundorum: a narrativa testemunhal em o conto da aia... Adriana Souza Machado Santana • Marcelo Ferraz de Paula

[...] Eu também li diversas memórias de prisão, memórias do Gulag, memórias dos campos de concentração, e pessoas que passaram por isso, pessoas que conseguiram vivenciar isso e, de algum modo, [...] conseguiram continuar sãos, focados e não morreram [...]. ${ }^{2}$ (PENGUIN RANDOM HOUSE, 2017, tradução nossa).

\section{Atwood e $O$ conto da aia}

Em O Conto da Aia vemos a narrativa se desenvolver pelo ponto de vista da personagem Offred, uma prisioneira em um "novo país" chamado Gilead, regido por um governo totalitário e leis/valores baseados numa religião que evoca os ideais da igreja calvinista. Neste espaço-tempo, a posição social das mulheres é definida segundo a capacidade de cumprir seu "destino biológico", ou seja, ter filhos. Elas também são proibidas de ler, escrever, trabalhar e ter bens em seu nome. Offred é uma das mulheres capazes de gerar bebês, porém o Estado a separa de sua filha e de seu marido, Luke, pois seu casamento é invalidado porque fora fruto de um adultério. Desse modo, ela é capturada e levada para o Centro Vermelho, onde passa por um treinamento para se tornar uma aia: mulheres enviadas para as casas dos Comandantes, cujas esposas não são capazes de gerar bebês saudáveis.

Recorrendo a uma estratégia político-literária que está na base das narrativas distópicas, a autora formula um futuro tenebroso, mais ou menos distante de nós, que amplifica - numa hipérbole terrível, mas perturbadoramente verossímil - os sintomas sociais de regressão visíveis no presente, exigindo do leitor uma reflexão ativa sobre os riscos desse futuro fictício tornar-se parcialmente real, pois:

2 No original: “[...] I also read a lot of prison memoirs, Gulag memoirs, concentration camp memoirs, and people who have got through, people who have managed through somehow [...], how they had managed to stay sane, keep focused, not die [...]". 
Nolite te bastardes carborundorum: a narrativa testemunhal em o conto da aia... Adriana Souza Machado Santana • Marcelo Ferraz de Paula

a distopia se apresenta como uma espécie de embaralhamento, uma fusão de diferentes temporalidades. Assim, enquanto a utopia era vista como um lugar no futuro, pensamos a distopia como um deslugar inscrito, acentuadamente, num determinado tipo de presente. (BENTIVOGLIO; CUNHA; BRITO, 2017, p. 8, grifo do autor).

Segundo Bloom (2014, p. 24, tradução nossa), "dessa maneira, Atwood deliberadamente aumenta e exagera a ideologia baseada em tradição da direita religiosa americana ou a maioria moral do início dos anos 1980, para examinar suas possíveis consequências sociais" ${ }^{3}$. Não deixa de ser interessante esse enlace entre a distopia - que lida com a construção imaginativa de um futuro difuso - e a narrativa testemunhal - envolta no descortinamento de um passado atestável pela experiência pessoal e histórica. Enquanto o testemunho visa recordar um passado traumático, mantendo viva a sua memória para que ele não se repita, a narrativa distópica formula um futuro sombrio e também se dirige como alerta ao tempo presente, para evitar que tal futuro concretamente ocorra. Construir o segundo explorando as nuances formais e éticas do primeiro, eis um elemento de originalidade do livro de Atwood e que explica parte importante da sua força literária e popularidade.

Entre as caminhadas diárias para o mercado com sua "companheira" Ofglen, nos é apresentado o dia a dia do regime gileadeano e os rituais dos quais as mulheres são obrigadas a participar, como as Rezavagâncias e Salvamentos. Offred também nos mostra como é a vida dentro da casa de um Comandante, o relacionamento com a Esposa Serena Joy, as Marthas Rita e Cora (empregadas responsáveis pelos cuidados com a casa e alimentação), o misterioso motorista Nick, que durante o desdobrar da história tornar-se-á seu amante, além das mensais Cerimônias nas quais a aia é estuprada pelo Comandante.

3 No original: "In this way, Atwood deliberately magnifies and exaggerates the tradition-based ideology of America's religious right, or moral majority of the early 1980 s, so as to scrutinize possible social consequences.". 
Nolite te bastardes carborundorum: a narrativa testemunhal em o conto da aia... Adriana Souza Machado Santana • Marcelo Ferraz de Paula

O livro é dividido em 46 capítulos numerados, e estes, por sua vez, separados em 15 seções com títulos variados, sendo o título "Noite" o único que se repete em várias seções. Temos também um epílogo intitulado "Notas Históricas", no qual somos apresentados à transcrição do Décimo Segundo Simpósio sobre Estudos Gileadeanos, na Universidade de Denay, em Nunavit, no dia 25 de junho de 2195. Nessa última parte do livro descobrimos que a narrativa que acabamos de ler é a transcrição de áudio de fitas cassetes antigas encontradas em um sítio arqueológico onde um dia foi a cidade de Bangor, localizada no estado do Maine (segundo o mapa atual dos Estados Unidos). O trabalho de transcrição foi realizado pelos professores James Darcy Pieixoto e Knotly Wade, mas é Pieixoto quem apresenta e discute o documento que eles nomearam como "O Conto da Aia".

Offred nos guia pela sua narrativa mostrando diversos aspectos da sua vida atual e passada, sempre com comentários reflexivos sobre como tudo a afetava, como as coisas mudaram tanto e como algo que antes era inaceitável se tornou cotidiano: “Qualquer coisa que esteja acontecendo é de costume. [...] Vivíamos, como de costume, por ignorar. [...] Nada muda instantaneamente: numa banheira que se aquece gradualmente você seria fervida até a morte antes de se dar conta" 4 (ATWOOD, 2017a, p. 71). Ela nos conta a sua história com um senso de responsabilidade agudo, incorporando no testemunho a sua vivência e a vivência de outras mulheres que passaram pelos mesmos sofrimentos, pois, conforme bem assinala Shoshana Felman (2000, p. 14), "um testemunho de vida não é simplesmente um testemunho sobre uma vida privada, mas um ponto de fusão entre texto e vida".

Nesse sentido, o relato de Offred demonstra uma marca testemunhal importante: ele é simultaneamente uma narrativa com uma dimensão coletiva, que visa relembrar outras mulheres em sua posição e fazer justiça a sua memória, e uma narrativa pessoal, íntima, que se sente impotente a alcançar um sentido "maior", edificante, para a matéria narrada. O primeiro capítulo é o único

4 No original: "Whatever is going on is as usual. [...] We lived, as usual, by ignoring. [...] Nothing changes instantaneously: in a gradually heating bathtub you'd be boiled to death before you knew it." (ATWOOD, 2017b, p. 56). 
Nolite te bastardes carborundorum: a narrativa testemunhal em o conto da aia... Adriana Souza Machado Santana • Marcelo Ferraz de Paula

em que Offred adota a primeira pessoa do plural, falando por um "nós" que abarca todas as aias, nomeadas ali com seus nomes de origem, e não pelo nome genérico atribuído pelo Estado. Nota-se um ato de solidariedade e re-humanização das vítimas por meio do testemunho, algo visível também no capítulo dedicado a Moira, no qual a narradora expressa com clareza esse compromisso ético, pois narrar a história da amiga é "uma maneira de mantê-la viva" 5 (ATWOOD, 2017a, p. 289).

Os demais capítulos são narrados por um "eu" que fala de sua própria vida, marcando a sua individualidade - o que também se configura como um ato de resistência diante do projeto de apagamento, visível em diversos atos do regime, como a uniformização das vestimentas, a vigilância constante e a subjugação das aias à vontade do Comandante. Offred sabe que sua narrativa emerge às margens da história oficial, enquadrando-se nas histórias de vida das vítimas: "Do ponto de vista da história futura, desse tipo, seremos invisíveis" ${ }^{6}$ (ATWOOD, 2017a, p. 270). Assim, narrar, para o sobrevivente, carrega algo de político e de terapêutico, ajudando a significar o trauma vivido e, assim, reconstituir uma identidade abalada pela dor: "Aquilo a que chamo de mim mesma é uma coisa que agora tenho que compor, como se compõe um discurso" 7 (ATWOOD, 2017a, p. 82).

Sua tarefa não é fácil, pois testemunhar não é algo confortável para o sobrevivente, uma vez que envolve, muitas vezes, lidar com o inenarrável, situações de violência tão extrema que parecem inacreditáveis. Além de tudo, como sobrevivente, a narradora não consegue trazer um testemunho completo da vivência em Gilead devido a sua posição como aia, com um olhar parcial sobre a estrutura de poder do país. Novamente segundo Shoshana Felman (2000), observamos que:

5 No original: "It's a way of keeping her alive." (ATWOOD, 2017b, p. 244).

6 No original: "From the point of view of future history, this kind, we'll be invisible." (ATWOOD, 2017b, p. 228).

7 No original: "My self is a thing I must now compose, as one composes a speech." (ATWOOD, 2017b, p. 66). 
Nolite te bastardes carborundorum: a narrativa testemunhal em o conto da aia... Adriana Souza Machado Santana • Marcelo Ferraz de Paula

O que o testemunho, no entanto, não oferece é um discurso completo, um relato totalizador desses eventos. Notestemunho, a linguagem está em processo e em julgamento, ela não possui a si mesma como uma conclusão, como constatação de um veredicto ou como saber em si transparente. (FELMAN, 2000, p. 18).

Para expressar a angústia do relato de Offred, Atwood incorpora diversas marcas textuais comuns a relatos testemunhais, como a fragmentação, a hesitação em narrar, o pudor de lidar com episódios mais tensos de sua história e a projeção de um leitor/ ouvinte a quem se busca comunicar o horror vivido. Ao explorar esses recursos narrativos em um romance abertamente ficcional, a autora reforça a carga política da obra e seu anseio de intervenção crítica sobre o presente.

A fragmentação está presente, sobretudo, em sua temporalidade partida. Temos três marcos temporais principais: o presente da enunciação clandestina de Offred, como aia na casa do Comandante; o do passado mais distante (que equivale ao nosso presente), no qual ela relembra a discreta ascensão do regime, evocando a sua vida familiar e profissional e a passividade da população em relação aos indícios de uma escalada autoritária no país; e, ainda, um período intermediário, que se passa no Centro Vermelho, onde convivia com as outras aias enquanto passava pelo cruel treinamento/lavagem cerebral liderado pelas Tias.

Estes tempos se alternam sucessivamente ao longo da narrativa, inclusive no interior de um mesmo capítulo. Na maior parte das vezes a passagem de um tempo para outro é marcada graficamente apenas por um espaço simples entre os parágrafos, embora em certos momentos, sobretudo os de maior aflição, eventos de diferentes épocas se sobrepõem em um mesmo parágrafo, marcando a desorientação da narradora e a impossibilidade de uma narração linear da experiência traumática. O momento presente, ela diz, é "onde não quero estar" 8 (ATWOOD, 2017a, p. 173), fazendo com que a memória, ainda que com suas fissuras habituais, transborde

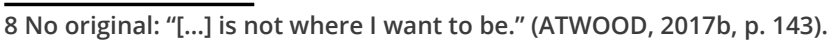


Nolite te bastardes carborundorum: a narrativa testemunhal em o conto da aia... Adriana Souza Machado Santana • Marcelo Ferraz de Paula

constantemente sobre o narrar: "Sou uma refugiada do passado e, como outros refugiados, repasso os costumes e hábitos de vida que deixei ou fui obrigada a deixar para trás" ${ }^{9}$ (ATWOOD, 2017a, p. 270). Assim, temos uma relação que evidencia que "o testemunho também é, de certo modo, uma tentativa de reunir os fragmentos do 'passado' (que não passa), dando um nexo e um contexto aos mesmos" (SELIGMANN-SILVA, 2005, p. 87, grifo do autor).

Em diversas partes do livro, Offred afirma que não deseja contar sua história: “Estou tentando não contar histórias, ou pelo menos não esta" 10 (ATWOOD, 2017a, p. 63), "Não quero estar contando essa história" 11 (ATWOOD, 2017a, p. 267-322). Em outro momento deseja o contrário, mas desejando que pudesse ser contada de uma maneira diferente: "Eu gostaria que essa história fosse diferente. Gostaria que fosse mais civilizada. Gostaria que me mostrasse sob uma luz melhor [...]" ${ }^{12}$ (ATWOOD, 2017a, p. 315). Offred chega a se revoltar contra o ato de narrar, questionando-se sobre o sentido de continuar sua narrativa, já que seria mais cômodo continuar em silêncio, ignorar tudo e se isolar dentro de si mesma. Ela diz:

Não quero contá-la. Não tenho que contar nada, nem para mim mesma nem para mais ninguém. Poderia apenas ficar aqui sentada, sossegadamente. Poderia me retirar. É possível ir tão longe para dentro, descer tão fundo e recuar tanto, que eles jamais conseguiriam fazer você sair. [...] Por que lutar? ${ }^{13}$ (ATWOOD, 2017a, p. 267).

Contudo, ela se força a continuar: mesmo que o ato de testemunhar seja doloroso, ela se cobra eticamente pela continuidade da história:

\footnotetext{
9 No original: “I'm a refugee from the past, and like other refugees I go over the customs and habits of being l've left or been forced to leave behind me [...]" (ATWOOD, 2017b, p. 227).

10 No original: "I am trying not to tell stories, or at any rate not this one." (ATWOOD, 2017b, p. 50).

11 No original: "I don't want to be telling this story." (ATWOOD, 2017b, p. 225-273)

12 No original: "I wish this story were different. I wish it were more civilized. I wish it showed me in a better light [...]" (ATWOOD, 2017b, p. 267)

13 No original: “I don't have to tell it. I don't have to tell anything, to myself or to anyone else. I could just sit here, peacefully. I could withdraw. It's possible to go so far in, so far down and back, they could never get you out. [...] Why fight?" (ATWOOD, 2017b, p. 225).
} 
Nolite te bastardes carborundorum: a narrativa testemunhal em o conto da aia... Adriana Souza Machado Santana • Marcelo Ferraz de Paula

Lamento que haja tanto sofrimento nesta história. [...] Mas não há nada que eu possa fazer para mudá-la. Mesmo assim me dói contá-la outra vez, mais uma vez. Uma vez não foi o bastante: uma vez não foi o bastante para mim na ocasião? Mas continuo com esta história triste e faminta e sórdida, esta história manca e mutilada [...]. Assim continuarei. Assim obrigo-me a continuar. 14 (ATWOOD, 2017a, p. 315-316).

O testemunho é encarado como um fardo pesado, mas necessário, improtelável. Seu relato é movido por um imperativo ético que conduz a uma autocrítica rigorosa, na qual reflete constantemente sobre o ato de narrar, a razão de sua insistência em deixar aquele registro e a forma adequada para cristalizar em esquivas palavras a sua recordação. Aqui se configura a tensão entre uma narrativa que se quer fiel aos acontecimentos narrados, mas, simultaneamente, se defronta com a necessidade constante de preencher lacunas, reinventar situações, pois sabe que "um filme sobre o passado não é igual ao passado" 15 (ATWOOD, 2017a, p. 279) e que, portanto, sua narrativa é uma reconstrução constante de escombros de memórias, vozes, pessoas e rastros.

Offred se depara, em suma, com o complexo problema da reconstrução da memória, uma tônica nas narrativas testemunhais. Ora ela se lamenta por não conseguir contar algo do modo como "realmente" aconteceu, ora recorre conscientemente à ficção para tecer versões diferentes de seu passado ou contar a história da maneira que ela gostaria que tivesse acontecido. Podemos identificar essa luta entre linguagem, narrativa e memória, por exemplo, no capítulo em que conta sua primeira visita ao quarto de Nick, apresentando três versões diferentes para o evento, cada uma delas desmentindo a anterior, acrescentando ou omitindo detalhes. O mesmo procedimento vemos ao final da narrativa da história de Moira, quando ela se mostra decepcionada por desconhecer o

\footnotetext{
14 No original: "I am sorry there is so much pain in this story. [...] But there is nothing I can do to change it. [...] Nevertheless it hurts me to tell it over, over again. Once was enough: wasn't once enough for me at the time? But I keep on going with this sad and hungry and sordid, this limping and mutilated story [...]. So I will go on. So I will myself to go on." (ATWOOD, 2017b, p. 267-268).

15 No original: "A movie about the past is not the same as the past." (ATWOOD, 2017b, p. 235).
} 
Nolite te bastardes carborundorum: a narrativa testemunhal em o conto da aia... Adriana Souza Machado Santana • Marcelo Ferraz de Paula

fim que a amiga teve e se divide entre o compromisso com a "realidade" e o desejo de fabular um destino menos sórdido para sua companheira:

Aqui está o que eu gostaria de contar. Gostaria de contar uma história sobre como Moira escapou, para sempre dessa vez. Ou se não pudesse contar isso, gostaria de dizer que ela explodiu a Casa de Jezebel, com cinquenta Comandantes dentro. Gostaria que ela acabasse com alguma coisa ousada e espetacular, um ultraje, algo que fosse adequado para ela. Mas até onde sei, isso não aconteceu, porque nunca mais voltei a vê-la. ${ }^{16}$ (ATWOOD, 2017a, p. 297).

Em seus embates com a narrativa, Offred tem consciência de que não é capaz de contar a história de maneira plenamente idêntica aos fatos, por isso deixa claro ao leitor que toda a sua narrativa é um artifício, dada a impossibilidade da linguagem abarcar integralmente a ferida do real traumático:

Isso é uma reconstrução. Tudo, cada detalhe é uma reconstrução. É uma reconstrução agora, em minha cabeça, enquanto estou deitada estendida em minha cama de solteiro, ensaiando o que deveria ou não deveria ter dito, o que deveria ou não deveria ter feito, como deveria ter feito o meu jogo. ${ }^{17}$ (ATWOOD, 2017a, p. 163).

Giorgio Agamben (2008), ao tratar dos testemunhos dos sobreviventes dos campos de concentração nazista, discute sobre essa dificuldade em narrar, segundo ele:

16 No original: “Here is what l'd like to tell. I'd like to tell a story about how Moira escaped, for good this time. Or if I couldn't tell that, I'd like to say she blew up Jezebel's, with fifty Commanders inside it. I'd like her to end with something daring and spectacular, some outrage, something that would befit her. But as far as I know that didn't happen. I don't know how she ended, or even if she did, because I never saw her again." (ATWOOD, 2017b, p. 250).

17 No original: "This is a reconstruction. All of it is a reconstruction. It's a reconstruction now, in my head, as I lie flat on my single bed rehearsing what I should or shouldn't have said, what I should or shouldn't have done, how I should have played it." (ATWOOD, 2017b, p. 134). 
Nolite te bastardes carborundorum: a narrativa testemunhal em o conto da aia...

Adriana Souza Machado Santana • Marcelo Ferraz de Paula

A dificuldade tem a ver com a própria estrutura do testemunho.

Por um lado, o que aconteceu nos campos aparece aos sobreviventes como a única coisa verdadeira e, como tal, absolutamente inesquecível: por outro, tal verdade é, exatamente na mesma medida, inimaginável, ou seja, irredutível aos elementos reais que a constituem. Trata-se de fatos tão reais que, comparativamente, nada é mais verdadeiro. (AGAMBEM, 2008, p. 20).

Ou seja, a dificuldade em narrar o horror do estado de exceção nasce do excesso de realidade com que a testemunha tem que lidar. Toda a matéria narrada é, para ela, presente e real, porém a palavra, a língua, não permite descrever a vivência em sua completude mutilada, tornando insuportável, indecorosa ou eticamente duvidosa a descrição dos detalhes terríveis necessários para que o relato se aproxime do terror vivido. Offred demonstra ciência de que o seu testemunho é lacunar e constitui uma reconstrução dos acontecimentos, pois "é impossível dizer alguma coisa exatamente da maneira como foi [...] você sempre tem de deixar alguma coisa de fora, existem partes, lados, correntes contrárias e nuances demais; gestos demais [...], formas demais [...], sabores demais [...]" 18 (ATWOOD, 2017a, p. 163).

Em meio ao impasse sobre o sentido e os limites de seu testemunho, a narradora também se dirige ao seu ouvinte/leitor. Em diversos momentos ela ultrapassa a introspecção clandestina da narrativa e conversa figurativamente com aquele que ouve/lê seu testemunho. Nessas passagens, podemos notar o intenso desejo de ser ouvida, em ter alguém a quem contar tudo aquilo: “[...] continuo com esta história triste e faminta e sórdida, esta história manca e mutilada, porque afinal quero que você a ouça, como ouvirei a sua também se algum dia tiver a chance, se encontrar você ou se você escapar [...]" 19 (ATWOOD, 2017a, p. 315).

\footnotetext{
18 No original: "It's impossible to say a thing exactly the way it was [...] you always have to leave something out, there are too many parts, sides, crosscurrents, nuances; too many gestures [...], too many shapes [...], too many flavors [...]" (ATWOOD, 2017b, p. 134).

19 No original: “[...] I keep on going with this sad and hungry and sordid, this limping and mutilated story, because after all I want you to hear it, as I will hear yours too if I ever get the chance, if I meet you or if you escape [...]" (ATWOOD, 2017b, p. 267-268).
} 
Nolite te bastardes carborundorum: a narrativa testemunhal em o conto da aia... Adriana Souza Machado Santana • Marcelo Ferraz de Paula

Para continuar contando sua história a narradora imagina alguém a quem contar, pois após tanto tempo em silêncio, quando finalmente consegue contar sua história, está solitária (como sugerido ao final nas Notas Históricas pelos professores que transcreveram as fitas), desse modo ela diz:

[...] se for uma história [...], devo estar contando-a para alguém. [...] Sempre existe alguma outra pessoa. Mesmo quando não há ninguém. [...] Caro você, direi. Apenas você, sem nome. Acrescentar um nome acrescenta você ao mundo real, que é mais arriscado [...]. Você pode ser mais de uma pessoa. Você pode significar milhares. ${ }^{20}$ (ATWOOD, 2017a, p. 52, grifo da autora).

Contudo, essa presença do outro se sabe precária e ilusória: "Fingirei que você pode me ouvir. Mas não adianta, porque eu sei que não pode" ${ }^{21}$ (ATWOOD, 2017a, p. 52). Desse modo, Offred também compartilha um temor presente nos testemunhos de sobreviventes. Em É isto um homem?, Primo Levi narra um sonho no qual está junto de familiares e amigos em sua casa, cheio de felicidade, quando começa a contar suas histórias do campo de concentração, mas ninguém o ouve, vão embora, deixando-o sozinho com suas palavras (LEVI, 1988, p. 85). O choque se dá porque o testemunho é transitivo, só se consuma ao comunicar a experiência vital da qual é nutrido. Por isso, a indiferença, a desconfiança e o desprezo seriam formas de replicação da violência sofrida. O destinatário ao qual Offred se dirige - um "você" indistinto, que pode ser a filha, Luke, Moira ou mesmo o leitor, ou todos eles simultaneamente - é condição para que o testemunho se consuma, para que as mulheres de que o livro trata não sejam novamente apagadas e a consciência do terror narrado não seja esquecida.

Novamente, essa abertura ao leitor/ouvinte é marcada por certa ambivalência. Se sua presença é condição para o testemu-

20 No original: “[...] if it's a story [...], I must be telling it to someone. [...] There's always someone else. Even when there is no one. [...] Dear you, I'll say. Just you, without a name. Attaching a name attaches you to the world of fact, which is riskier [...]. You can mean more than one. You can mean thousands." (ATWOOD, 2017b, p. 39-40, grifo da autora).

21 No original: "I'll pretend you can hear me. But it's no good, because I know you can't." (ATWOOD, 2017b, p. 40). 
Nolite te bastardes carborundorum: a narrativa testemunhal em o conto da aia... Adriana Souza Machado Santana • Marcelo Ferraz de Paula

nho, o testemunho, ao fundar este outro, também cria uma companhia para a narradora, deixando-a menos solitária ao configurar, na linguagem, uma presença, ainda que precária, de alguém querido: "Conto, portanto você existe" 22 (ATWOOD, 2017a, p. 316). Ou seja, o testemunho funda na própria linguagem essa alteridade que ele elege como destinatário. As passagens em que a narradora se dirige ao leitor são as que apresentam um teor metalinguístico mais acentuado, pois ela deixa de olhar para a história que está contando de dentro e passa a olhá-la de fora, para refletir sobre o seu ato, reconhecer e enfrentar os seus limites. Como narradora, ela discute consigo mesma o seu modo de contar, o porquê de estar contando e frequentemente se desculpa e/ou se justifica para o leitor sobre o modo como conta a história:

\begin{abstract}
Eu gostaria que essa história fosse diferente. Gostaria que fosse mais civilizada. Gostaria que me mostrasse sob uma luz melhor, se não mais feliz, pelo menos mais ativa, menos hesitante, menos distraída por trivialidades. Gostaria que tivesse mais forma. Gostaria que fosse sobre o amor [...]. ${ }^{23}$ (ATWOOD, 2017a, p. 315).
\end{abstract}

Além das marcas propriamente textuais/formais do testemunho na construção de $O$ conto da aia, observamos que obras como essa também fornecem dados históricos, como os utilizados na construção ficcional de Atwood. Diversas estratégias de controle do regime fundamentalista de Gilead são retomadas de outros governos totalitários: o apagamento da subjetividade das pessoas, a repressão sexual, a adulteração deliberada do passado, a uniformização, a criação de uma linguagem do poder, com seus códigos e eufemismos ${ }^{24}$, o apoio em mitos e dogmas regressivos. As semelhanças ocorrem sobretudo com o regime nazista, que aparece literalmente no romance quando se comenta a diferença entre o tratamento dado aos judeus nos campos de concentração e o

22 No original: “I tell, therefore you are." (ATWOOD, 2017b, p. 268).

23 No original: "I wish this story were different. I wish it were more civilized. I wish it showed me in a better light, if not happier, then at least more active, less hesitant, less distracted by trivia. I wish it had more shape. I wish it were about love [...]." (ATWOOD, 2017b, p. 267).

24 Atwood cria, a rigor, uma novilíngua gileadiana, com diversos termos e neologismos que nomeiam suas práticas e visam escamotear a violência nelas contidas: Destino biológico, Colônias, Traidores de gênero, Olhos e um longo etecetera. 
Nolite te bastardes carborundorum: a narrativa testemunhal em o conto da aia... Adriana Souza Machado Santana • Marcelo Ferraz de Paula

modo como foram tratados em Gilead (ATWOOD, 2017a, p. 174). Porém, a referência aos Gulags soviéticos também é evidente, seja na passagem em que a narradora se sente como "uma exilada russa em Paris" ou nos expurgos que ocorrem em Gilead ao fim do romance, assim como o sequestro dos filhos das vítimas, que evoca, por sua vez, as ditaduras latino-americanas, principalmente a argentina. Assim, o romance vai tecendo uma nítida e assustadora relação de retomada e aperfeiçoamento de práticas de dominação ao longo da história, pois, como o próprio texto diz, “havia muito pouco de verdadeiramente original ou nativo em Gilead: sua genialidade foi a síntese" ${ }^{25}$ (ATWOOD, 2017a, p. 361).

Segundo Frederick Petterson, Gilead utiliza dois tipos principais de dispositivo para manter o domínio sobre as mulheres. 0 primeiro é a linguagem, pois elas não são autorizadas a ler ou escrever e precisam se adequar a uma série de códigos vazios, desde os cumprimentos e saudações expressos em fórmulas mecânicas obrigatórias até a perda do nome próprio; e o segundo é a violência legalizada pelo governo (PETTERSON, 2010, p. 4). Desse modo, os homens, que são minoria, mantém o domínio sobre as mulheres e, apesar de toda a opressão, algumas mulheres que concordam com o regime, como as Tias, assumem cargos de "poder", contribuindo para a manutenção e perpetuação do regime opressor vigente.

\section{Nolite te bastardes carborundorum}

Dentro do testemunho de Offred há a presença de um outro micro-testemunho que condensa poeticamente as questões que abarcamos até aqui. Ele está contido na expressão em latim Nolite te bastardes carborundorum, deixada pela aia anterior que servia à casa a qual Offred foi atribuída e que provavelmente cometeu suicídio, conforme relato do seu Comandante. A inscrição fora feita

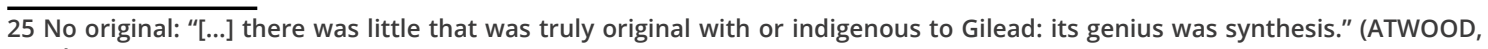
2017b, p. 307). 
Nolite te bastardes carborundorum: a narrativa testemunhal em o conto da aia... Adriana Souza Machado Santana • Marcelo Ferraz de Paula

no armário da aia, "em letras minúsculas", com "um alfinete ou talvez apenas uma unha, no canto onde caía a sombra mais escura" ${ }^{26}$ (ATWOOD, 2017a, p. 65), e tem uma função importante ao longo do romance, sendo retomada várias vezes durante a narrativa. Em nossa leitura, tomamos a expressão como uma metáfora pungente do testemunho, deixada de maneira clandestina por outra vítima do regime de Gilead. Em sua concisão extrema e enigmática, até pela escrita cifrada numa língua antiga, a frase sintetiza nuances fundamentais da escrita testemunhal: desejo de comunicar e denunciar uma situação de penúria, registro ativo de que alguém vivenciou aquela situação e não se calou, ato de resistência que deixa uma marca no espaço do inimigo, cumplicidade com outras vítimas as quais a sua mensagem visa confortar, alertar e fazer companhia.

Ao descobrir que a frase significa "Não deixe que os bastardos esmaguem você", seu sentido imediato é desvendado e sublinha a ideia de alerta e incentivo à resistência, mas não dissipa os significados construídos anteriormente. Até então, seu sentido semântico era misterioso para a narradora, mas suas funções se diversificavam. Ela era tomada como mantra ou oração: "Rezo silenciosamente: Nolite te bastardes carborundorum. Não sei o que significa, mas me soa correto, apropriado, e terá que servir, pois não sei mais o que dizer a Deus. Não agora." 27 (ATWOOD, 2017a, p. 111, grifo da autora). Era também uma ordem, um chamado, "um triste grafite, rabisco abandonado"28 (ATWOOD, 2017a, p. 222). A inscrição em latim exalta o poder da palavra em um contexto de mutilação da subjetividade das personagens; ela aproxima as muIheres que sofreram o mesmo drama e serve de alento e consolo, ao mesmo tempo em que expressa um ato de rebeldia, um vestígio de seu anseio por gritar. Nolite te bastardes carborundorum ecoa, portanto, ao longo do testemunho de Offred como um com-

26 No original: “[...] a tiny writing [...] scratched with a pin or maybe just a fingernail, in the corner where the darkest shadow fell [...]" (ATWOOD, 2017b, p. 52).

27 No original: “I pray silently: Nolite te bastardes carborundorum. I don't know what it means, but it sounds right, and it will have to do, because I don't know what else I can say to God. Not right now." (ATWOOD, 2017b, p. 90).

28 No original: "[...] a sad graffiti, scrawled once, abandoned." (ATWOOD, 2017b, p. 186). 
Nolite te bastardes carborundorum: a narrativa testemunhal em o conto da aia... Adriana Souza Machado Santana • Marcelo Ferraz de Paula

promisso com a aia anterior, de levar suas palavras adiante, em respeito ao seu sofrimento:

\begin{abstract}
Agrada-me refletir sobre essa mensagem. Agrada-me pensar que estou em comunhão com ela, essa mulher desconhecida [...]. Agrada-me saber que sua mensagem tabu conseguiu chegar a pelo menos outra pessoa, que se fez carregar por si mesma, deixada sobre a parede de meu armário, foi aberta e lida por mim. Por vezes repito as palavras para mim mesma. Elas me dão uma pequena alegria. ${ }^{29}$ (ATWOOD, 2017a, p. 66).
\end{abstract}

No outro extremo da postura acolhedora e respeitosa de Offred, que incorpora ao seu testemunho o testemunho de outra mulher, confirmando sua cumplicidade em relação àquelas que passaram pelas mesmas situações degradantes que ela, o livro termina com um exemplo aterrador de como o testemunho pode ser esvaziado pela comunidade leitora. As Notas Históricas, que servem como epílogo da obra, abordam um evento acadêmico que ocorre em 2195, muitos anos depois do testemunho da nossa personagem principal e já também após a ruína de Gilead. Novamente a projeção temporal é subvertida: a narrativa futurista que lemos em nosso presente passa a ser lida como documento de um passado distante, examinada em um congresso de historiadores. Nesse evento, alguns professores e estudiosos ilustres, provenientes de várias regiões do mundo, se reúnem para tratar de questões voltadas ao regime estabelecido em Gilead. O Professor Pieixoto, da Universidade de Cambridge (responsável pela descoberta, transcrição e organização do testemunho de Offred), apresenta um breve texto acadêmico comentando a história da narradora e detalhes das fitas caseiras onde constavam seu relato, bem como o processo de transcrição do áudio para a forma escrita.

\footnotetext{
29 No original: "It pleases me to ponder this message. It pleases me to think I'm communing with her, this unknown woman. [...] It pleases me to know that her taboo message made it through, to at least one other person, washed itself up on the wall of my cupboard, was opened and read by me. Sometimes I repeat the words to myself. They give me a small joy." (ATWOOD, 2017b, p. 52).
} 
Nolite te bastardes carborundorum: a narrativa testemunhal em o conto da aia... Adriana Souza Machado Santana • Marcelo Ferraz de Paula

Ao emular o discurso acadêmico, com seus trejeitos e convenções, Atwood desenvolve, com fina ironia, uma crítica ao modo como lidamos, na universidade e fora dela, com os testemunhos de sobreviventes de regimes de exceção. A fala de Pieixoto fundamenta-se numa presunção de neutralidade e distanciamento em relação ao objeto que analisa. Seus comentários, de teor tecnicista, historiográfico ou filológico são marcados pela frieza e restringem o testemunho de Offred ao caráter de fonte histórica. Ele lamenta, em mais de uma ocasião, que a autora do relato não tenha oferecido mais detalhes sobre o cotidiano de sua época, como a sugerir que ela havia se excedido no exame de seus sentimentos, em detrimento de uma descrição mais pormenorizada de seu meio:

[...] muitas lacunas permanecem. Algumas delas poderiam ter sido preenchidas por nossa autora anônima, tivesse ela tido outra maneira de pensar. Poderia ter nos contado muito sobre o funcionamento do império de Gilead, se tivesse tido os instintos de uma repórter ou de uma espiã. ${ }^{30}$ (ATWOOD, 2017a, p. 364).

Também é a pretensão científica de neutralidade que faz Pieixoto evitar uma crítica mais incisiva ao regime de Gilead. O pesquisador afirma que:

[...] devemos ser cautelosos ao fazer um julgamento moral sobre a sociedade de gileadeana. Sem dúvida já aprendemos a essa altura que tais julgamentos são por necessidade específicos de cultura. Além disso, a sociedade gileadena estava submetida a grandes pressões de caráter demográfico e outros [...]. Nosso trabalho não é censurar e sim compreender. (Aplausos.) 31 (ATWOOD, 2017a, p. 355).

\footnotetext{
30 No original: "[...] many gaps remain. Some of them could have been filled by our anonymous author, had she had a different turn of mind. She could have told us much about the workings of the Gileadean empire, had she had the instincts of a reporter or a spy." (ATWOOD, 2017b, p. 310).

31 No original: “[...] we must be cautious about passing moral judgment upon the Gileadeans. Surely we have learned by now that such judgements are of necessity culture-specific. Also, Gileadean society was under a good deal of pressure, demographic and otherwise [...]. Our job is no to censure but to understand. (Applause.)" (ATWOOD, 2017b, p. 302, grifo da autora).
} 
Nolite te bastardes carborundorum: a narrativa testemunhal em o conto da aia... Adriana Souza Machado Santana • Marcelo Ferraz de Paula

O juízo relativístico do pesquisador em relação ao sistema de Gilead, endossado pelos aplausos da plateia de intelectuais, demonstra uma perspectiva histórica que se omite em relação ao caráter político da rememoração e a necessidade de se constituir uma crítica firme em relação às ameaças do autoritarismo. Tal postura do pesquisador faz o romance ser concluído de maneira pessimista, pois fica patente em sua fala a dificuldade de aprendermos com o passado e de ouvirmos, com atenção e rigor, mas também com respeito e empatia, o testemunho das vítimas. Jean Marie Gagnebin (2006, p. 75) sublinha em ruas reflexões o risco do debate sobre as catástrofes "calar os gritos dos agonizantes sob a tagarela e complacente disputa entre especialistas". É exatamente essa a postura de Pieixoto, que começa a sua fala com um estúpido gracejo, de forte teor machista, com a pesquisadora que the apresenta ao público.

Em 2195, como em Gilead, como em nossa contemporaneidade, o risco de uma regressão fundamentalista permanece presente, bem como a dificuldade de se ler, ouvir, acolher e aprender com o testemunho das vítimas. O epílogo do romance pode ser lido como uma teoria do testemunho às avessas, isto é, uma denúncia sobre como não se ler o testemunho e, por extensão, o próprio romance. Finalmente, em $O$ conto da aia, sua construção testemunhal estabelece um relato de vida pungente e doloroso, que projeta ficcionalmente um futuro tenebroso, resultante de nossa dificuldade em ler os indícios das ameaças históricas que se acercam de nós, mas também chama atenção para a recusa geral em ouvir essas vozes do passado que ecoam, como alerta, no presente.

\section{Referências}

AGAMBEN, Giorgio. 0 que resta de Auschwitz: o arquivo e a testemunha (Homo Sacer III). Tradução: Selvino J. Assman. São Paulo: Boitempo, 2008. 
Nolite te bastardes carborundorum: a narrativa testemunhal em o conto da aia...

ATWOOD, Margaret. O conto da aia. Tradução Ana Deiró. Rio de Janeiro: Rocco, 2017a.

ATWOOD, Margaret. The Handmaid's Tale. Reino Unido: Vintage Books, 2017b.

BENTIVOGLIO, Júlio; CUNHA, Marcelo Durão R. da; BRITO, Thiago Vieira de (org.).

Distopia, literatura \& história. Serra: Ed. Milfontes, 2017.

BLOOM, Harold. Margaret's Atwood: The Handmaid's Tale

(Bloom's guides). New York: Infobase Publishing, 2014.

BRADBURY, Ray. Fahrenheit 451. Tradução: Cid Knipel. São Paulo: Biblioteca Azul, 2012.

FELMAN, Shoshana. Educação e crise Ou as vicissitudes do ensinar. In: SELIGMANN-Silva, M.; NESTRÓVSKI, A. (org.). Catástrofe e representação. São Paulo: Escuta 2000. p. 13-72.

FERREIRA, Aurélio Buarque de Holanda. Miniaurélio: o minidicionário da língua portuguesa. 7 ed. coord de ed. Marina Baird Ferreira; eq. de lexicografia Margarida dos Anjos. Curitiba: Ed. Positivo, 2008.

GAGNEBIN, Jeanne Marie. Lembrar escrever viver. São Paulo: Editora 34, 2006.

HUXLEY, Aldous. Admirável mundo novo. Tradução: Vidal de Oliveira. São Paulo: Biblioteca Azul, 2014.

LEVI, Primo. É isto um homem? Tradução: Luigi Del Re. Rio de Janeiro: Rocco, 1988.

MARCO, Valéria de. A literatura de testemunho e a violência de estado. Lua nova, s. v., n. 62, p. 45-68, 2004.

ORWEL, George. 1984. Tradução: Heloísa Jahn. São Paulo: Cia. das Letras, 2009.

PENGUIN RANDOM HOUSE. The Handmaid's Tale: Margaret Atwood and showrunner Bruce Miller (full panel) BookCon 2017. 2017. (57min18sec). Disponível em: https://www.youtube. com/watch?v=tFqJ8wqupwk\&t=1s. Acesso em: 20 jan. 2020. 
Nolite te bastardes carborundorum: a narrativa testemunhal em o conto da aia... Adriana Souza Machado Santana • Marcelo Ferraz de Paula

\section{PETTERSON, Fredrick. Discourse and oppression in Margaret}

Atwood's The Handmaid's Tale. School of Languages and Literature/ English, Linnaeus University, 2010. Disponível em: http://www.diva-portal.org/smash/get/diva2:321781/fulltext01. pdf. Acesso em: 5 abr. 2020.

SELIGMANN-SILVA, Márcio. Apresentação da questão: a literatura do trauma. In: SELIGMANN-SILVA, Márcio (org.). História, memória, literatura: o testemunho na Era das Catástrofes. Campinas, São Paulo: Editora da Unicamp, 2003a.

SELIGMANN-SILVA, Márcio. Reflexões sobre a memória, a história e o esquecimento. In: SELIGMANN-SILVA, Márcio (org.). História, memória, literatura: o testemunho na Era das Catástrofes. Campinas, São Paulo: Editora da Unicamp, 2003b.

SELIGMANN-SILVA, Márcio. Testemunho e a política da memória: o tempo depois das catástrofes. Proj. História, São Paulo, v. 30, s. n., p. 71-98, jun. 2005. 